\title{
Demedicalizing misery: Welcoming the human paradigm in mental health nurse education
}

\section{Introduction}

In 2013 in the UK, the Division of Clinical Psychology (DCP) of the British Psychological Society released a position statement. This called for a paradigm shift in mental health towards a conceptual system that is no longer based on a "disease" model' (Johnstone 2014, p15). The arguments for changed practice and understandings in this document are supported in contemporary critical mental health work at an international level (eg Bentall, 2010; Boyle and Johnstone, 2014; Cromby et al., 2013; Johnstone, 2014; LeFrancois et al., 2013; Thomas, 2014).

The authors of the DCP (2013) position statement do not deny the role of biology in mediating and enabling all forms of human behaviour and distress. They also acknowledge complex relationships between social, psychological and biological factors underpinning mental health problems (Cromby et al., 2013). Their key message is that there is a lack of empirical support for biology as a primary cause in what are currently commonly regarded as 'functional' mental health problems. Functional mental health problems, treated across the range of in-patient and community mental health services, are distinguishable from organic problems by an absence of signs of brain impairment.

To date, no genes, biomarkers or evidence for disease processes have been convincingly identified for functional mental health problems. Instead, accepting the importance of evolved human biology and cultural mediators in patterns of human emotional reaction, an overwhelming amount of evidence points to the causal role of social and relational adversities in their development (Boyle and Johnstone, 2014; Cromby et al., 2013; Johnstone, 2014; Thomas, 2014). These adversities can be roughly divided into two groups: social circumstances subsume various forms of social inequality, such as unemployment, discrimination, poverty, poor housing and living environments, adverse events in childhood and adolescence, and social isolation. Relationship factors include varieties of victimisation, emotional, physical and sexual abuse in childhood and adulthood, and loss and bereavement.

It should be emphasised that 'distress' in the above context does not mean disease' or 'disorder'. For this reason, the position statement and related critical literature make clear that a change of language is needed to understand, conceptualise, research and help in alleviating human misery. In moving from technological to human paradigmatic understandings, narrative-based approaches, including the central role of formulation, emerge as a more credible way forward. 


\section{The Technological Paradigm}

The technological paradigm assumes that interlinked, faulty physiological, emotional and information processing mechanisms are key to understanding extremes of human misery (see Thomas, 2014). This assumption is reflected in an increasing colonization of human experience and behaviour by medical and psychiatric language. In various forms, biomedical understandings have generally dominated mainstream psychiatric theory and practice for 150 years (Thomas, 2014). Since the early 1950s however, psychiatric diagnosis has been more specifically spearheaded by the diagnostic development committee work of the American Psychiatric Association (Johnstone, 2014).

The technological paradigm privileges and promotes pharmaceutical and related psychological interventions that fit with its medicalized assumptions. These interventions are by definition context-independent in regarding internal processes as causal in human distress. They can therefore be applied relatively independently of concerns about the impact of relationships or personal values - information conveyed by service users in their narratives of lived experiences. It is therefore not surprising that such narratives are often regarded as andecdotal and/or diagnostically symptomatic, and therefore irrelevant to mainstream institutional psychiatric treatment (Johnstone, 2014; Thomas, 2014).

\section{The Human Paradigm}

In contrast, the emerging human paradigm regards mental health work and recovery from distress as embodied moral practice, grounded in material and cultural circumstances and personal histories and relationships. It therefore values context and meaning as crucial in understanding human distress, and pays the utmost respect to how suffering people interpret and story their experiences of this (Boyle and Johnstone, 2014; Grant and Leigh-Phippard, 2014; Grant et al., 2015; Johnstone, 2014; Thomas, 2014).

The human paradigm rests on the simple idea of human life as narrative. The concept of narrative or storied identity emerged as a philosophical concern in the second half of the $20^{\text {th }}$ century, in the work of philosophers such as Rorty and Maclntyre, who argued that people's lives are inescapably grounded in their experiences of time. So like novels or plays, but in much more messy ways, human lives have beginnings, middles and ends, and plots and sub-plots along the way. Our life narrative behaviours, experiences and decisions are thus only understandable to the extent that they are embodied in historical contexts. To put this more simply, what guides our understandings of 
ourselves is knowledge of what stories we're in at any one point at time. Similarly, other people's understandings of us inform how they locate us in their accounts of what we're doing and our motivations behind our actions (Thomas, 2014). This has implications for what constitutes good mental health work: this arguably occurs when service user and worker stories about each other merge and chime sympathetically and in harmony, rather than jar in discord.

\section{Problems with the Technological Paradigm}

How well do psychiatric diagnostic systems fare as moral practices in storying lives from the perspective of the human paradigm and evidence-based scrutiny? They fall down as both a credible categorising and coherent system in two major ways. The scientific criterion of reliability refers to the consistency of judgements made about mental health service users' diagnoses. Diagnostic reliability emerges from the literature as consistently low, and influenced by such factors as different diagnostic preferences held by different psychiatrists (Johnstone, 2013; Thomas, 2014) and relatively unconscious judgements that reflect and reinforce white western norms about what constitutes culturally normal experiences and behaviours (Johnstone, 2013). As a result of these and related factors, 'People typically collect a whole range of diagnoses as they progress through the (psychiatric) system, and are often prescribed a whole range of different medications on the basis of...guesswork' (Johnstone 2014, p23).

Psychiatric diagnoses also fail on the scientific criterion of validity, or describing what actually exists. Given that, as described above, there are no sites of functional 'mental illness' that can be seen in human bodies, diagnostic categories do not describe things in the real world. Instead, diagnoses are made on the basis of psychiatrists' and other mental health workers' observations of people's mood, thinking and related aspects of their subjective states (Johnstone, 2013; Thomas, 2014).

Having the status of social and cultural, rather than medical or evidence-based, judgements, it is remarkable that diagnoses have endured to date as fundamental to the work of mental health nurses and their colleagues. In this context, the medicalized language used in diagnostic understandings - replete as it is with terms such as 'symptoms', 'illness', 'pathology' and 'prognosis' - conceals an ideological rhetorical function. Reflecting and reifying lay assumptions, it is constantly accepted as the authoritative narrative, received and believed by many service users and their carers: that the former group are suffering from a diagnosable illnesses, perhaps caused by biochemical imbalances, best treated In hospitals, with medication prescribed and administered by doctors and nurses. 


\section{The Psychosocial Impact of Diagnosis}

Also concealed is the fact that there are problems related to psychiatric diagnosis at the level of relationships in and between professional and user communities. These result in incoherent stories conferred on the latter groups (Johnstone, 2014; Grant and Leigh-Phippard, 2014; Grant et al., 2015). Johnstone (2014), for example, makes the point that when involved in mainstream institutional psychiatric services, service users are often caught in a double bind, reflected in the message that 'although it's not your fault that you are ill, you are responsible for your illness. You must therefore make the effort to get better (so long as you do it our way as we are the illness experts).'

This, institutional-led rather than collaborative, recovery dynamic was further illuminated in a recent, internationally-focused integrative literature review of mental health service users' experiences of mental health care. Newman et al. (2015) describe a lack of user involvement in the care planning process as a major finding. These authors argue that this stems from limited opportunities reported by users to express their views about both their care needs and what should be included in their care plans. They report that where this is achieved, service user involvement is often rarely implemented, in spite of policy directives to the contrary.

This tension at the heart of care planning speaks to a related tension between the meaning of 'recovery' at institutional psychiatric and service user levels, and arguably gives rise to circumstances where users may be judged on the basis of how well they comply with the dominant narratives of institutional psychiatry (Newman et al., 2015; Stacey and Stickley, 2012). Thus, users can be perceived as being either too dependent or non-compliant, lacking in insight through rejection of a diagnosis or too reliant on it and avoidant of life responsibilities. Overall, this proves to be a no-win situation for many service users, which contributes to why some make a reasoned choice to use deceit and subterfuge to manage their relationships with the psychiatric services in the interests of their personal integrity (Grant and Leigh-Phippard, 2014; Grant et al., 2015; Johnstone, 2014).

A further problem has been described as the 'treatment barrier'. This refers to how, according to the logic of a diagnostic model of mental distress, problems are located within individuals rather than in social or relationship difficulties (Johnstone, 2014). This gives, for example, abusive partners licence to avoid culpability, and also enables mental health services to blame individuals for the intractability of their problems, without these services acknowledging the extent to which 
involvement in psychiatric services has contributed to their development (Grant and Leigh-Phippard, 2014; Grant et al., 2015).

As mentioned above, if personal experiences are regarded as simply diagnostic symptoms, there seems little reason for mental health professionals to make too much of an effort to explore their meanings. As a result of this state of affairs, '...people can spend years coming in and out of hospital without anyone sitting down and discussing their experiences and their distress in order to make sense of them.' (Johnstone 2014, p.53). Reflecting monologic rather than dialogic organizational cultural styles in many mental health services, and a corresponding lack of collaborative care planning, people are often told what their problems are. In the absence of their involvement in discussions, or their agreement about how accurate this information feels to them, this can threaten relationships and trust between users and mental health workers, and the recovery process (Grant and Leigh-Phippard, 2014; Grant et al., 2015; Newman et al., 2015).

Stopping people from telling their stories, thus having these stories respected and validated by mental health professionals, also relates to the 'confirmation bias' phenomenon, frequently occurring in mental health treatment settings (Thomas, 2014). This refers to the act of mental health workers actively selecting information from and about users of their service that fits their medicalized views of them. Users in turn may well self-select when telling their stories to match these views, and mental health nurses often see users' neutral or contextually understandable behaviours in terms of the official psychiatric stories conferred on them.

\section{Emerging Human Paradigm Principles}

In light of the above, nurses should be taught to put ethics before technology as a fundamental overarching principle. In practice, this demands always privileging and according deep respect to the meaning and context of people's suffering, conveyed in narratives of the lived experience of their distress (Johnstone, 2014; Stacey and Stickley, 2012; Thomas, 2014; Warne and McAndrew, 2007).

Lived experience knowledge rather than diagnostic categories should therefore be the point of departure and major focus for mental health nurses in understanding and helping people. The emerging dialogue then becomes the basis for the facilitated re-shaping of a person's life based on a recovery relationship characterised by mutuality of trust (Grant and Leigh-Phippard, 2014; Grant et al., 2015; Johnstone, 2013, 2014; Thomas, 2014). Such dialogues, shaped as individual formulations of people's problems, emerge as the viable alternative to diagnosis (DCP, 2013; Johnstone, 2013, 
2014). Formulations should explicitly acknowledge the basis for an individual's distress in social circumstances and relationship factors, the frequent significance of childhood adversity in broader contexts of social inequality (Thomas, 2014), and relevant social and cultural mediators, shapers and moderators of adversity (Boyle and Johnstone, 2014).

However, as with psychiatric diagnostic judgements, the formulation process is intrinsically subjective and open to bias (Johnstone, 2013). That said, Johnstone argues that - as individual, open ended and developing, accounts of human distress rather than diagnostic categories - formulations do not logically need to meet scientific standards of reliability and validity. Perhaps a more prescient potential problem is that, in line with enduring institutional trends, they may be developed unilaterally by mental health nurses and other workers, with insufficient respect paid to users' narratives of lived experience. This highlights the current relevance of an editorial comment made almost a decade ago: that mental health nurses must be more collaborative and thoughtful about the vocabulary they use for engaging with clients' experiences (Happell 2007).

In the service of recovery, the task of according narrative respect and developing formulations constructed in a de-medicalised language, mental health nurse educators need to help nurses develop increasingly more sophisticated levels of narrative competence. Celebrated and practiced to some degree in general medicine and psychiatry (Thomas, 2014), with corresponding work emerging in nursing and mental health nursing (Bach and Grant, 2015), this term refers to the capacity for human beings to deeply absorb, interpret, and appropriately respond to the stories of others. Such close attention facilitates methods for addressing users' existential issues around inner hurt, despair, hope grief, and moral pain.

In the broader context of facilitating emotional and transformation learning in mental health nurse education (Stacey and Stickley, 2012), narrative competence should privilege hearing over listening (Thomas, 2014). By carefully attending to context, nuance and difference within and between people's experiences of distress, narratively competent practice is helpful in engaging people who use mental health services in a recovery process through which they are able to re-story their lives (Grant and Leigh-Phippard, 2014; Grant et al., 2015; Thomas, 2014).

It should not however be assumed that narrative competence is a given in either the natural abilities or current training of mental health nurses. Nurses skilled and willing to exercise narrative competence in the spirit of recovery from an existential rather than institutional branding 
perspective are often likely to do so in spite of rather than in line with their organisational realities of practice. They may arguably therefore be the exception rather than the rule in some mental health services (Grant and Leigh-Phippard, 2014; Grant et al., 2015).

\section{Implications for Nurse Education}

To what extent do contemporary undergraduate mental health nurse curricula support and promulgate, or, conversely, violate the principles outlined above, at local and policy levels? Evidence-based mental health nursing practice and communicative competence is fundamental to UK Nursing and Midwifery Council Standards for Pre-registration Nursing Education. However, in the light of my argument so far, in my own university, the biomedical approach to understanding mental health problems is taught alongside other models in mental health nurse education with insufficient levels of criticality. The extent to which this may be happening in other higher educational nursing programmes internationally, in the context of pharmaco-centric mental health nurse educational assumptions (Lakeman and Cutcliffe, 2009), is an open question.

However, I am in possession of informally collected ethnographic data that speaks to this issue. Subsequent to the release of a recorded seminar of my demedicalizing mental health work on social media, a mental health curricular lead nurse academic from a university in the north of England who had seen this recording contacted me early in 2015 , to say:

...we are in a double-bind. We might not be teaching the biomedical model as a 'current model', but more from a critical social history perspective, but that would not fit with practice. We often hear via students from their mentors about whether or not we teach nursing students what (mentors) view as being 'needed in practice' - ie psychiatric nursing practice. A question that arises for me then is: Can a 'demedicalised nursing approach'... thrive and take root in clinical environments where this is not the accepted practice? Hence we have this rather unsatisfactory middle-ground where we tacitly condone the (biomedical) model to some extent by saying 'well we shouldn't be doing this; we shouldn't be using this approach, but you'll find yourself working in clinical areas where (it's required).'

The power of the dominant service curricula described by this academic is also played out in the phenomenon of many student mental health nurses in my own institution continuing to talk almost exclusively in the language of psychiatric diagnosis at the completion of their studies. For these students, and possibly others in different parts of the UK and elsewhere, this is perhaps not surprising. From a university in the south of England, two students who had also accessed my recording made contact with me. They told me about their experiences on a psychopharmacology module, within which they were taught, uncritically and in the absence of adequate supporting 
evidence, that there is a 'General agreement (of a) strong correlation between schizophrenia and over-activity of dopamine transmission hypothesis' (bullet point from module powerpoint presentation, which they shared with me).

\section{Threats to Progress}

The sustained absence of evidence to support the technological paradigm's medicalization of human distress as a convincing narrative begs the question as to why its exclusivity and hegemony has endured for so long. In this regard, the picture of competing academic and service curricula described above needs to be contextualised in more powerful landscapes. It is clearly the case that psychiatric medication has played a major part in alleviating suffering in the $20^{\text {th }}$ and $21^{\text {st }}$ centuries. However, a consensus in the critical mental health literature is that the elective affinity between global corporate pharmaceutical and related interests and mainstream institutional psychiatry has played an exclusive role in determining constructions of reality for mental health service users and workers, and related research, professional and policy agendas underpinning these constructions. As an example, Lakeman and Cutcliffe (2009) point to unwarranted confidence in the biological causation of mental health problems and related pharmaco-centrism, expressed by some mental health nursing scholars in the absence of adequately supporting evidence.

In this broad cultural context, psychiatric diagnosis may be regarded as a political device employed to legitimate social control activities which, if its ideological nature, cultural significance and lack of evidence-base were exposed, would arguably receive greater levels of critical public scrutiny. Critique of its practices, assumptions and allegiances are already at its heart: Johnstone (2014) describes how key people in the development and construction of the Diagnostic and Statistical Manual of Mental Disorders (DSM) of the American Psychiatric Association have spoken out about the relationship between their diagnostic system, in its successive editions, and its association with global pharmaceutical industries over the years. She also points out that over two-thirds of members of the advisory task force for the current edition have apparently been shown to have links to these industries. Enormous profits continue to be made by offering pharmacological solutions to human misery, and these are key to the continuing development of the DSM and its burgeoning diagnostic categories.

Finally, advancing social justice in mental health by exposing the above poses further challenges for positive change at the levels of professional education and access to welfare benefits. These, in turn mask wider social inequalities within which mental health nurses and their educators are implicated 
through 'guilt by association'. Currently the training and status of psychiatrists and nurses is justified by the diagnostic approach, while for service users psychiatric diagnoses carry with them the necessary exchange value for social security. It's very hard to for people in the UK who experience extreme psychological distress to access benefits, social housing and other structural forms of social support without a diagnosis, while having one in the USA gives access to government health schemes such as Medicaid and medical insurance.

From a social justice perspective, in spite of the obstacles to change, the arguments presented in this paper point up the need for furthering and developing human paradigm work in mental health nurse educational curricula, since:

... vulnerable and disturbed people are not always welcome as relatives, friends or neighbours; it may suit all of us to see them as suffering from a medical problem which is someone else's role to treat. The alternative solutions - providing housing and employment, tacking poverty, re-building communities are far more challenging and expensive.

(Johnstone 2013, p113)

\section{References}

Bach, S., Grant, A., 2015. Communication \& Interpersonal Skills in Nursing. Third Edition. Learning Matters/SAGE Publications Ltd., Exeter.

Bentall, R.P., 2010. Doctoring the Mind: Why Psychiatric Treatments Fail. Penguin Books, London.

Boyle, M., Johnstone, L., 2014. Alternatives to psychiatric diagnosis. Lancet Psychiatry. Published Online October 2, 2014. http://dx.doi.org/10.1016/S2215-0366(14)70359-1 [accessed November 1, 2014].

Cromby, J., Harper, D., Reavey, P. 2013. Psychology, Mental Health and Distress. Palgrave Macmillan, Basingstoke. 
Division of Clinical Psychology, 2013. Classification of Behaviour and Experience in Relation to Functional Psychiatric Diagnoses: Time for a Paradigm Shift. British Psychological Society, Leicester. Available from http://shop.bps.org.uk/classification-of-behaviour-and-experience-in-relation-tofunctional-psychiatric-diagnoses-time-for-a-paradigm-shift.html.

Grant, A., Leigh-Phippard, H., 2014. Troubling the normative mental health recovery project: The silent resistance of a disappearing doctor. In: Zeeman, L., Aranda, K., Grant, A. (Eds.). Queering Health: Critical challenges to normative health and healthcare. PCCS Books, Ross-on-Wye.

Grant, A., Leigh-Phippard, H., Short, N.P., 2015. Re-storying narrative identity: a dialogical study of mental health recovery and survival. Journal of Psychiatric and Mental Health Nursing. 22, 278-286.

Happell, B., 2007. 'A rose by any other name...': The use of language in mental health nursing practice. International Journal of Mental Health Nursing. 16, 223.

Johnstone, L., 2013. Diagnosis and Formulation. In: Cromby, J., Harper, D., Reavey, P. Psychology, Mental Health and Distress. Palgrave Macmillan, Basingstoke.

Johnstone, L., 2014. A Straight Talking Introduction to Psychiatric Diagnosis. PCCS Books, Ross-onWye.

Lakeman, R., Cutcliffe, J.R., 2009. Misplaced epistemological certainty and pharmaco-centrism in mental health nursing. Journal of Psychiatric and Mental Health Nursing. 16, 199-205.

LeFrancois, B.A., Menzies, R., Reaume H. (Eds.), 2013. Mad Matters: A Critical Reader in Canadian 
Mad Studies. Canadian Scholars' Press Inc., Toronto.

Newman, D., O’Reilly, P., Lee, S.H., Kennedy, C., 2015. Mental health service users' experiences of mental health care: an integrative literature review. Journal of Psychiatric and Mental Health Nursing. 22, 171-182.

Stacey, G., Stickley, T., 2012. Recovery as a threshold concept in mental health nurse education. Nurse Education Today. 32, 534-539.

Thomas, P., 2014. Psychiatry in Context: Experience, Meaning \& Communities. PCCS Books, Ross-onWye.

Warne, T., McAndrew, S., 2007. Passive patient or engaged expert? Using a Ptolemaic approach to enhance mental health nurse education and Practice. International Journal of Mental Health Nursing. 16, 224-229. 